is naturaleza 


\section{NATURALEZA Y LIBERTAD}

Revista de estudios interdisciplinares

Número 1

Málaga, 2012

Esta revista es accesible on-line en el siguiente portal: http://grupo.us.es/naturalezayl/ 


\section{Naturaleza y Libertad}

Revista de estudios interdisciplinares

Número 1

Directores: Juan Arana, Universidad de Sevilla; Juan José Padial, Universidad de Málaga; Francisco Rodríguez Valls, Universidad de Sevilla.

Secretaria: Avelina Cecilia Lafuente, Universidad de Sevilla.

Consejo de Redacción: José Luis González Quirós, Universidad Juan Carlos I, Madrid; Francisco Soler, Universität Dortmunt / Universidad de Sevilla; Pedro Jesús Teruel. Universidad CEU Cardenal Herrera; Héctor Velázquez, Universidad Panamericana, México.

Consejo Editorial: Mariano Alvarez, Real Academia de Ciencia Morales y Políticas; Allan Franklin, University of Colorado; Michael Heller, Universidad Pontificia de Cracovia; Manfred Stöcker, Universität Bremen; William Stoeger, University of Arizona.

Consejo Asesor: Rafael Andrés Alemañ Berenguer. Universidad M. Hernández de Elche; Juan Ramón Álvarez, Universidad de León; Luciano Espinosa, Universidad de Salamanca; Miguel Espinoza, Université de Strasbourg; José Manuel Giménez Amaya, Universidad de Navarra; Karim Gherab Martín, Urbana University, Illinois; Martín López Corredoira, Instituto Astrofísico de Canarias; Alfredo Marcos, Universidad de Valladolid; Javier Monserrat, Universidad Autónoma de Madrid; Leopoldo Prieto, Colegio Mayor San Pablo, Madrid; Ana Rioja, Universidad Complutense, Madrid. Madrid; José Luis Rodríguez Recio, Universidad Complutense, Madrid; Javier Serrano, TEC Monterrey (México); Hugo Viciana, Université

Paris I; Claudia Vanney, Universidad Austral, Buenos Aires; José Domingo Vilaplana, Huelva.

\section{Redacción y Secretaría:}

Naturaleza y Libertad. Revista de estudios interdisciplinares. Departamento de Filosofía y Lógica. Calle Camilo José Cela s.n. E-41018 Sevilla.

Depósito Legal: MA2112-2012

๔ 954.55.77.57 Fax: 954.55.16.78. E-mail: jarana@us.es

๑ Naturaleza y Libertad. Revista de Filosofía, 2012 


\section{ÍNDICE}

MANIFIESTO

\section{ESTUDIOS}

Rafael Andrés Alemañ Berenguer. Universidad Miguel Hernández de Elche

La relación mente-materia y el monismo neutral.

Fernando García-Cano Lizcano. Ciudad Real

Evolucionismo y utopia de género

Miguel Ángel Herrero. Universidad Politécnica de Madrid

Instrumentalismo y realismo en la física de James C. Maxwell...

Juan Miguel Suay Belenguer. UNED

La mente mecánica.

José Luis Yepes Hita. Universidad de Murcia

Los «Anales de Física» de L.W. Gilbert.

DisCUSIONES

Francisco José Soler Gil. Universidad de Sevilla - T. Universität Dortmund

¿Se puede naturalizar la epistemología?

Antonio Diéguez. Universidad de Málaga

La opción naturalista. Una respuesta a Francisco Soler

Francisco José Soler Gil. Universidad de Sevilla - T. Universität Dortmund

¿Qué menos que un milagro podría salvar la epistemología naturalista? .265

Antonio Diéguez. Universidad de Málaga

Filosofía sin milagros. Comentarios finales a la contrarréplica de Francisco Soler ...273

CRÍTICA DE LIBROS

Pedro Jesús Teruel, Filosofia y ciencia en Hipatia, (Ángel Martínez Sánchez) . 285 Noticias y COMENTARIOS

Miguel Palomo, Universidad de Sevilla

Si no hay cuerpo, no hay mente: una discusión sobre consciencia y libertad. 
Naturaleza y Libertad. Revista de estudios interdisciplinares. Número 1, 2012. ISSN: 2254-9668

\title{
LOS ‘ANALES DE FÍSICA’ DE L.W. GILBERT Y SU INFLUENCIA EN LA NATURPHILOSOPHIE DE SCHELLING Y HEGEL
}

\author{
José Luis Yepes Hita \\ Universidad de Murcia
}

Resumen: Presentamos a Ludwig Wilhelm Gilbert, editor de la prestigiosa revista científica de Halle y Leipzig los Annalen de Physik. Cuando en torno a 1800 inició esta serie, todavía subsistía en las universidades alemanas la química del flogisto, y muchas traducciones suyas de los avances de la École Polytechnique y del círculo de Manchester anticiparon el cambio de paradigma de la nueva química y la llegada del atomismo con sus nuevos elementos. Ésta fue la tópica de fondo mientras las facultades de Filosofía impartían una nueva asignatura, la Naturphilosophie. Apuesta innovadora que Goethe favoreció en Jena, aunque pretendía también rivalizar con la trayectoria más severa y tradicionalista de la Escuela de Minas de Freiberg. Un desconocido Hegel se inició en la universidad de Jena enseñando esta materia bajo el padrinazgo de Schelling. Pero pronto Hegel se desmarca de él interiorizando las críticas que la revista de Gilbert estaba lanzado contra Schelling y sus seguidores, los románticos Naturphilosophen. La "raíz común” en el finalismo de la Crítica del Juicio, el esquematismo fichteano o la autosuficiencia del Yo y la intuición intelectual en Schelling, dejaban abierta una evasiva mística que impedía a la ciencia su pronunciamiento, justamente en un momento en que la ciencia había rebasado ya con la química los límites mecanicistas de la razón pura ilustrada. Hegel supo ver este cambio de fase y este choque generacional. El vocabulario especulativo que luego le hará célebre en Berlín, Aufhebung, absoluto y dialecticidad, lo acuñó Hegel en estos semestres de Jena y sobre esta tópica de la naturaleza, cuando extractaba para el manuscrito de sus clases los descubrimientos de Winterl, Berthollet, Dalton, Prévost o Erxleben, y seguía las críticas de británicos como Chenevix o Guyton de Morveau contra los románticos alemanes. Concluye, así, que las nuevas leyes de la lógica deben reflejar el estado actual de 
la Física, así como la racionalidad los nuevos acontecimientos de la Historia americana y europea.

Palabraz clave: Gilbert, Hegel, Schelling, Naturphilosophie, Física, Quimismo, Dialecticidad, Aufhebung, el Sistema de Jena, manuscritos de 1803/04, Románticos, Origen de la revista científica alemana (Annalen der Physik), últimos flogistas alemanes, investigadores de la École Polytechnique, Berthollet, Winterl y Chenevix

Abstract: We introduce the editor of Annalen der Physik (Leipzig). He is a defender of the new antiflogist French chemistry when, in around 1800s, the old methods still existed: in Gotinga, for example, Lichtenberg. With this in-depth topic, the Faculty of Philosophy presents a new subject, the Naturphilosophie. It was a proposal which Goethe favoured competing with Freiberg's Mine School. Hegel began in Jena University teaching this subject under Schelling's patronage. But soon he disassociated from him by familiarazing with the criticism that Gilbert's magazine was hurled against Schelling and the Romantics. Later remarkable term such as Aufhebung, Absolute and dialectialism, coined by Hegel in those years summarizing Dalton, Chenevix, Winterl, Guyton, Berthollet, Fischer, Ritter and Steffens's articles, from Gilbert's magazine. Against the aesthetic/mystic evasion of the kantianism or the intellectual intuition according to Fichte and Schelling, Hegel reaffirms a new Logic reflection of the Physics of his time (neither mechanic nor illustrated) just as the rationality will be in the History that he lives.

Key words: Gilbert, Hegel, Schelling, Natural Philosophy, Physics, Chemical Synthesis, Dialectic, Aufhebung, the system of Jena, manuscripts from 1803/04, Romantics, the birth of the German scientific periodical (Annalen der Physik), the last German flogistic chemists, researchers of the polytechnic school, Dalton and the Manchester School, Berthollet, Winterl y Chenevix.

Recibido: 21/02/2011. Aprobado: 10/12/2011. 
Naturaleza y Libertad. Revista de estudios interdisciplinares. Número 1, 2012. ISSN: 2254-9668

\section{INTRODUCCIÓN}

Presentamos al editor de los Annalen der Physik (Leipzig). Defensor de la nueva química francesa antiflogista cuando, en torno a 1800, todavía subsistían los viejos métodos: en Gotinga, por ejemplo, Lichtenberg. Con esta tópica de fondo, las facultades de Filosofía ofrecen una nueva asignatura, la Naturphilosophie. Fue una apuesta que Goethe favoreció rivalizando con la Escuela de Minas de Freiberg. Hegel se inició en la universidad de Jena enseñando esta materia bajo el padrinazgo de Schelling. Pero pronto se desmarca de él interiorizando las críticas que la revista de Gilbert estaba lanzado contra Schelling y los románticos. Términos luego célebres como Aufhebung, absoluto y dialecticidad, los acuñó Hegel en estos años extractando artículos de Dalton, Chenevix, Winterl, Guyton, Berthollet, Fischer, Ritter y Sttefens, de la revista de Gilbert. Contra la evasiva estético/mística del kantismo o la intuición según Fichte y Schelling, Hegel se reafirma en una nueva Lógica reflejo de la Física de su tiempo (ni mecánica ni ilustrada), tal como la racionalidad habrá de serlo de la Historia que vive.

\section{PRESENTACIÓN}

Los Anales de Fisica se recibían por suscripción a casa del destinatario. Solían leerlos profesionales y funcionarios. Llegaban al buzón sólo los cuatro cuadernillos sin guillotinar de cada tomo para que el suscriptor los encuadernara a su gusto. En este caso, el Dr. Parrot, en el puerto más lejano del Báltico, nos da un ejemplo. Su carta al director tiene unas palabras iniciales que no dejan de ser irónicas: 
Naturaleza y Libertad. Revista de estudios interdisciplinares. Número 1, 2012. ISSN: 2254-9668

Aquí en nuestra región hiperbórea recibimos de nuevo los productos literarios de nuestra querida Alemania y así también algunos fascículos de sus Anales. No le puedo decir cómo me ha alegrado y animado después de echarlos tanto tiempo en falta ${ }^{1}$.

Hay otro interés en los descubrimientos de los Anales de Física que sintoniza muy bien con el romanticismo de Hegel (una «Naturaleza que oculta al Espíritu»). Y es el hecho de cuantificar parámetros imponderables. Las leyes científicas descifradas durante la Ilustración bajo dominio del newtonianismo medían distancia, duración y peso. Ahora, los experimentos en el gabinete se decidían en cualidades como luz, calor, potencial eléctrico y magnético.

El rumbo que imprimió Gilbert estaba más en sintonía con lo que agradaba a Napoleón, que exhortaba al mundo editorial a trabajar al modo de la revista de Física de Jean Claude Delamétherie², en línea con otros proyectos como los que lideraban Fourcroy, Berthollet y Hassenfratz.

1 «Vermische physikalische Bemerkungen von Herr. Prof. Parrot in Riga» en Annalen der Physik (en lo sucesivo abreviado como Ann.) (1802) t. X: 166.

2 Journal de Physique. Obsérvese que el título es homónimo de la revista alemana fundada por Gren, Journal der Physik. Gilbert sucede a Gren y actualiza la publicación como Annalen der Physik. Delamétherie fue una de las fuentes principales de Gilbert. Delamétherie había llenado de alguna manera el hueco dejado por el abad François Rozier (1734-1793) con sus Observations sur la Physique, y que tanto apreció Lavoisier (en las que publicó una de sus memorias más decisivas — 26 de abril de 1775— sobre el aumento de peso de los metales tras la calcinación). Delamétherie había publicado en tres tomos, en 1795: Théorie de la Terre (Maradan, París); el último de esos tomos lo dedicaba a la «formación de los vegetales y de los animales», bajo una concepción que compartió perfectamente Goethe. De interés para la Filosofía del momento fue Considérations sur les êtres organisés (L. Perronneau/Courcier, Paris, 
Naturaleza y Libertad. Revista de estudios interdisciplinares. Número 1, 2012. ISSN: 2254-9668

\section{VIDA DE GILBERT}

Los abuelos de Ludwig Wilhelm Gilbert procedían de Metz. Eran hugonotes, habían huido de la región de Lorena y entraron a pie en Alemania. La represión contra los calvinistas significó para Francia una verdadera guerra civil y una quiebra moral de la conciencia. El cardenal Richelieu recortó sus actividades en Montpellier, Montauban y La Rochelle con sucesivas medidas, que fueron algo así como un antiedicto de Nantes. En muy pocos días, decenas de miles de franceses dejaron la región camino de Suiza y Alemania. Por sus costumbres austeras, rigor y formación artesanal, fueron muy bien acogidos. Sólo en 1788, los hugonotes se verían rehabilitados para el Estado francés; pero ya era sólo una satisfacción sobre el papel. Para entonces L.W. Gilbert era ya un joven berlinés de 19 años. Había nacido en la capital prusiana el 12 de agosto de 1769, hijo menor de Ludwig Dietrich Gilbert, originario de Fehrbellin, que ejerció la abogacía hasta llegar a fiscal en el tribunal de sala de la corte de Berlín. De los primeros recuerdos de su padre, Gilbert conservó una curiosidad casi matemática por la Geografía: países y ciudades, cambios de jurisdicción, toponimia, lindes y aduanas. La lectura de un mapa y la ubicación del lugar que habitamos reconforta interiormente, y la orientación en él, el concepto abstracto más prematuro que concebimos. La enseñanza de la Geometría olvidaba el forzamiento antinatural que su-

año XIII -1804-). Y las lecciones sobre Geología que mantuvo en el Collège de France las publicaría en 1816 (Veuve Courcier, París). 
pone fijar medidas y distancias de referencia. Geometría y Álgebra acompañaron siempre todos los cambios sustanciales de la Filosofía moderna, y hacia mediados del XVIII todavía compartían una misma idealidad cognoscitiva.

Gilbert quedó huérfano de padre el 7 de octubre de 1775, cuando sólo contaba seis años. La madre lo envió al año siguiente a una institución filantrópica en Dessau y, junto con otros niños, suizos en su mayoría, aprovechó las primeras clases, adquiriendo una vocación por la Matemática al cuidado del profesor Busse ${ }^{3}$. Durante este periodo de formación, Gilbert estuvo alojado en casa de Kolbe, un experto calcógrafo sobre plancha de cobre, oficio bien apreciado entonces, pues permitía a las imprentas valorizar sus trabajos. Así fue como Gilbert adquirió esta afición por las artes gráficas.

Con 17 años obtuvo una beca para la universidad de Halle. Desde aquella primavera en que se instaló allí, frecuentó a figuras de la ciencia: Eberhard,

3 Era prácticamente el estreno de una nueva Pedagogía que se hizo frecuente en ambientes evangélicos. El centro de Dessau, conocido como el Philanthropium, se fundó en 1774. Entre los profesores que más influían en ese modelo educativo, estaba Johann Bernhard Basedow (1724-1790), que decía seguir las teorías de Rousseau, pero en muchos aspectos la aplicación que hicieron fue muy peculiar. Defendieron una religión natural, pero no tanto en la línea de Hume, pues explicaban también pasajes bíblicos. Con la religión natural Basedow proponía un método de adquisición de conocimientos fundado en la intuición y en atender a la lección de las pequeñas cosas. Además, otras áreas llenaron sus horas de aprendizaje: salud, higiene y deporte, así como la observación del entorno agrícola, juegos, excursiones y trabajos manuales. Cuando Gilbert estaba a punto de doctorarse debió recibir con más dolor que nostalgia la desaparición del Philanthropium (1793). Las obras de Basedow circulaban traducidas al francés por Huber, aunque impresas en Leipzig — que era ya la gran capital editorial de Alemania-: Nouvelle Méthode d'Éducation (Fritsch, Leipzig, 1772). 
Bartels, Karsten, Richter, Madeweis, Voigtel, Reichardt, Spatzier, Müller, Schwerin y Sprengel. Sus estudios principales siguieron siendo la Geografía y la Matemática. El 15 de diciembre de 1794 se doctoró en Filosofía en Halle (Magister). Al siguiente año daba clases de Matemática y de Física, lo que conllevaba un puesto de investigador en el observatorio astronómico. $\mathrm{Y}$ en 1798, además, otro cargo como subbibliotecario; de este lugar y fecha data su encuentro casi providencial con F.A.C. Gren, pues se puso a su servicio para la revista que éste editaba, el Neues Journal der Physik; hasta ese momento la publicación germana más prestigiosa del ámbito experimental, el monumento más oportuno sobre las preguntas del flogisto y el lugar donde todos aprendieron la doctrina del calor, la Meteorología, etc.

Al morir Gren el 26 de noviembre de $1798^{4}$, Gilbert se hizo cargo de la revista. La refundación de la obra como Annalen der Physik se inicia exactamente en 1799 con una periodicidad cuatrimestral. En 1801 fue nombrado también profesor para el puesto que había dejado vacante Gren, y en 1811 es llamado a Leipzig como profesor de Física y Química.

4 La Sociedad de amigos naturalistas de Berlín incentivó una producción muy intensa entre 1795 y 1803, abordando casi monográficamente series de Mineralogía y Electricidad. Como asociación remonta su fundación a más de veinticinco años antes; coincidió esta conmemoración con el fallecimiento de Gren; entonces, la publicación de referencia de dicha asociación (Der Gesellschaft naturforschender Freunde zu Berlin, Neue Schriften) sacó un artículo homenaje de sus compañeros, 1799, tomo II, págs. 404-413, en el que se pronunciaron numerosas personalidades, algunos de las cuales serán luego muy prolíficos en los Anales de Física, como D.L.G. Karsten, J.A. De Lüc, E.F.F. Chladni y S. Hermbstädt. De manera que Gilbert supo congraciarse con ellos para que la asociación actuara como nodriza de su revista y adaptación a los tiempos. 
Gilbert fue un oportuno traductor. Como viajero, es también el caminante a rincones apartados que unía en intereses a una Alemania con fronteras cambiantes, y luego más desordenadas desde 1803 por las levas para el ejército de Napoleón. Así plasmó aquella vocación por la Geografía en Manual de viajes por Alemania (Handbuch für Reisende durch Deutschland), que, entre otras novedades, aporta datos cartográficos y geomineros sobre el macizo del Harz ${ }^{5}$. También recorrió Westfalia Rhin abajo, a cuya Sociedad ducal de Mineralogía perteneció — como el mismo Hegel— desde 1804; le acompañó el ingeniero de Montes Hêron de Villefosse ${ }^{6}$, que era el inspector

5 Contiene apartados que sirvieron de guía para identificar moneda y cambios de divisa en muy pocos kilómetros de recorrido. Su excelencia ante el lector provenía del numismático y experto químico en materia de fundición que era. También tiene una selección de rutas por grandes ciudades, los cambios de postas más importantes y mapas diseñados por él. Las tablas con la distribución del correo (internacional) son muy precisas. La primera parte de este Handbuch für Reisende, publicada en Leipzig en 1791, detallaba bien todas las posesiones de Prusia y Austria. La segunda parte la dedicó a Baviera y a los ducados de Sajonia; salió al público en 1792. El tercer volumen lo dedica a Lusacia, al Estado de Hannover y a toda la topografía completa del Harz, que con mucha alegría recibirían los vecinos de Jena; salió en 1795.

6 Antoine-Marie Hêron de Villefosse (1774-1852) publicará en 1819 La richesse minerale. A propósito de la Exposición de París sobre productos industriales franceses, escribió Rapport fait au jury central de l'Exposition des produits de l'industrie française de l'année 1819 sur les objets relatifs à la métallurgie (Huzard, París, 1820), y que volvió a actualizar con ocasión de la Exposición del año 27. También Mémoire sur l'état actuel des usines à fer de la France, considérées au commencement de l'année 1826, avec un supplément relatif à la fin de cette même année, présentant un aperçu des mines de bouille de la France et des usines à fer de la Grande-Bretagne (Huzard, París, 1826). De su trabajo en Alemania y colaboración con Gilbert publico 
francés de minas y maquinaria. Esta región, que emergía políticamente como entidad propia, debía tributar por gastos de guerra a Francia. En otra ocasión viajó a Suiza, y de allí a Lyon y París. Y, al menos una vez al año, volvía sobre sus pasos de adolescente y visitaba a su madre y a sus cinco hermanas en Potsdam. Gilbert fue una persona de costumbres ordenadas que dedicaba las horas más tempranas a la confección de los Anales de Física. También las últimas horas del día. Domina el francés, y probablemente tenía conocimientos de holandés, italiano e inglés.

El título de su disertación para Halle en 1795 fue:

De natura, constitutione et historia matheseos primae vel universalis seu metaphysices mathematicae commentatio ${ }^{7}$.

Por el contenido y por la fecha, es muy probable que Hegel la conociera o que supiera ya de Gilbert por esta actuación para ser habilitado allí. Piénsese que Hegel lee su disertación De Orbitis planetarum en Jena, en agosto de 1801, centrado en Kepler y las leyes de la Astronomía. Gilbert defendía en aquel documento $-\mathrm{y}$ será un talante que posea su revista - la necesidad de fundamentar matemáticamente la Física y aritmetizar exhaustivamente parámetros y resultados del laboratorio, una actitud pedagógica similar a la que abiertamente proponía también por entonces en Inglaterra Dalton.

Los datos que aquí vertimos sobre la biografía de Gilbert proceden del obituario que se publicó en su propia revista. Ludwig Choulant (1791-1861),

«Nivellement des Harzgebirges mit Barometer» en Ann. (1808) t. XXVIII, pags. 49-104, en el que especificaba sobre detallados perfiles orograficos las vetas de cobre.

7 Comentario sobre la Naturaleza, sobre la constitución y la historia de los primeros conocimientos o de la Matemática universal o Metafísica. 
miembro de la Academia de Medicina y Cirugía de Dresde y un experto en Historia de la Medicina ${ }^{8}$, fue el encargado de hacer esta necrológica. Poco antes, Gilbert le había publicado sus análisis sobre los componentes del opio ${ }^{9}$. Choulant, en las visitas que hizo a Leipzig, y al conocerle en la cercanía de su vida privada, habla de él como una persona de «voluntad decidida» y que mostraba en general el «modo de pensar científico» ${ }^{10}$. Le sorprendieron los numerosos extractos que llevaba preparados, no sólo para la cuidada redacción de los Anales, sino para las clases, sobre todo para las horas de Física y de Química en la universidad, así como para las conferencias en los Privatcollegia sobre Óptica, Mecánica y combinaciones químicas. Todo ello con el inconveniente de una salud y complexión débil, como detalladamente nos certifica Choulant:

\footnotetext{
Por una debilidad en el crecimiento, una construcción corporal afeada [...] se acostumbró más al retraimiento y a la actividad aíslado en su mesa de estudio. Este modo de vida le condujo también por Leipzig, y ahí estaban además los profesores Krug, Keil, Gehler, Mollweide, Heinroth, Clodius, el consejero de finanzas Campe, el consejero municipal Rochlitz, el parlamentario Auger, el librero Barth, D. Hillig, el comerciante Reichenbach, el barón von Uckermann de Wesenstein, entre otros, que eran su compañía habitual. Gilbert estaba soltero, pero con buena relación social con señoras educadas y simpáticas. En
}

8 Escribió junto a Johann Friedrich Pierer una obra seriada: Medicinisches Realwörterbuch zum Handgebrauch practische Ärzt und Wundärzte und zu belehrender Nachweisung für gebildete Personen aller Stände. Grimmer, Dresde, 1816/1829.

9 «Beweis, daß sich das reine Morphium mit der Koblensäure zu einem neutralen kristallisirbaren Salze verbindet» en Ann. (1818) t. XXIX, págs. 412-419.

10 Ann. (1824) t. LXXVI: 465. 
sus expresiones [tenía] un alto grado de pureza, siempre decoroso y vestido con gusto, y muy auténtico para conversar en ambientes cultos, diversos y finos; frecuentaba los mejores círculos y era valiosa su presencia, una compañía alejada de toda pedantería que, a menudo, por medio de una graciosa ejecución sabía aplicar opiniones paradójicas, y por educación situarse en oposición contra la mayoría; también por esto se agradecía su presencia. Y, por eso también, el profesor G. Hermann en su charla en el círculo académico pudo decir de él: «bastante bonachón y abnegado, sin falsedad y sin mala opinión de nadie, era de un trato apasionado y ameno, que alegraba tantas veces el círculo de amistades con bromas y con invitación a la broma $[\ldots]$

Entre su legado dejó:

...una rica colección de más de 7000 planchas consistentes en valiosos grabados de cobre, especialmente del nuevo periodo de Edelink hasta [Giovita] Garavaglia, etc. ${ }^{11}$

La colección de minerales de Gilbert también tenía un significado especial, pues ejemplares venidos de los cinco continentes tenían una alta cotización en los mercados de París y Londres, y eran la base sobre la que se montaban en laboratorio análisis con electricidad. Campe custodió esta colección. El instrumental de experimentación, aparatos sobre todo eléctricos y neumáticos, se registró en una caja con número de catálogo 357. Y su amplia colección de libros, nutrida de obras de Geografía, Matemática, Física y Química, se subastó en Leipzig el 15 de noviembre de 1824 con el número 3056. La colección estaba enriquecida también con mapas, planos y tablas astronómicas. El artículo que Choulant tituló «Ensayo sobre la vida y obra de 
Ludwig Wilhelm Gilbert» explica así esos principios teóricos admitidos desde joven por Gilbert:

\begin{abstract}
El inhóspito genio creador dirige a algunos a entregarse con predilección a ramas particulares de su ciencia, a alcanzar desde ellas nuevas perspectivas, a ampliarla por medio de nuevos descubrimientos, a esclarecer mediante nuevas explicaciones, y así emprender con ellas quizá una transformación, o preparar como tal una que continúe dominando por mucho tiempo y sea considerada una mejora esencial de la ciencia. A otros, por el contrario, les atrae más, según su orientación espiritual, abarcar con un golpe de vista el todo de la ciencia, velar por el perfeccionamiento formal de la misma, reunir lo existente y clasificar con lucidez, despachar la divulgación de novedades, pero también examinar y seleccionar las mismas para que sólo lo depurado se emplee en la magnífica construcción de la ciencia. Que ambos caminos son merecedores de la ciencia, necesarios e igualmente respetables, y que reformadores de todas las ciencias se pueden encontrar en ambos caminos, es innegable, y los nombres de Newton y Bacon de Verulam podrían por sí solos explicar lo dicho. Pero, sobre todo, depende de esto: que el erudito tanto de un camino como de otro reconozca verdaderamente su vocación y persiga incesantemente aquello para lo que está determinado por la Naturaleza ${ }^{12}$.
\end{abstract}

Esta visión de la ciencia que inmediatamente percibían sus más próximos colaboradores es también la que se contagia a Hegel para sus cursos de $\mathrm{Na}$ turphilosophie. Efectivamente, Gilbert fue generoso abriéndose a otros campos de investigación, no es monocromático, no abusa explicitando sólo su tópica preferida (Astronomía y Meteorología), ni tampoco en las novedades químicas que explicaba en clase. Esta visión de conjunto es personalmente suya como editor, aunque conociera por formación y trayec- 
toria la Filosofía kantiana. La publicación como tal pronto empezó a dejar obsoletas otras que pretendían proporcionar ese estilo enciclopédico, manuales o diccionarios, que escolástica y alfabéticamente disecan conceptos sólo con ejemplos del pasado. La labor académica habitual de la universidad, el extracto, empezaba a demandar otros textos. Los Anales lograban su cometido reflejando el estado vivo de la ciencia con numerosas voces coordinadas por contraste.

La revista de Gilbert fue un receptor oportunísimo de los mejores avances de Gran Bretaña, Holanda, Francia, Italia, etc. La comunicación que mantuvo con instituciones extranjeras era fluida y rápida. Los actos públicos en el Instituto Nacional de París, los Transactions de la Royal Society en sus sedes de Londres, Edimburgo y Dublín, en la Literary and Philosophical Society de Manchester (familiarmente conocida como la Lit and Phil), en la Academia de Turín, y tantos otros, son los focos de interés del Gilbert editor, y con ellos entrevera cada número de la revista, que ya de por sí empezaba enriquecida.

Un hombre, que desde hace varios años trató en conferencias académicas conjuntamente la Física y la Química, y cuyo empeño principal fue lograr [una] perspectiva sin interrupción de estas ciencias, debería albergar el deseo de elaborar un Manual de lo mismo; hubiera sido ciertamente muy natural. Y a pesar de todo, nunca consiguió realizar este cometido. En el año 1804 entregó a la editorial de Schrader los Fundamentos de la Teoría experimental de la Naturaleza (Hamburgo 1797, en octavo), a lo que él se decidió por la petición de una segunda edición mejorada de este libro que apareció realmente (también Hamburgo 1804, octavo); sólo que él se previene expresivamente en el prólogo: "que de ningún modo sería lo que se dice propiamente un manual de Física, respecto a la cual prefiere no introducir aún varios principios”. Quedó por esto de forma general la disposición del original, y Gilbert señaló sus añadidos y mejoras por medio de paréntesis. Sucedió 
completamente lo mismo cuando en el año 1812 empezó la tercera edición de estos Fundamentos (Leipzig, por Cnobloch), pero sólo terminaría hasta la página 18. Se puso tan grandes exigencias para un manual de Física, como poco fue lo que pudo aprovechar de ese trabajo, y, por eso mismo, durante muchos años de su vida acarició escribir propiamente un manual ${ }^{13}$.

Perteneció a las siguientes asociaciones científicas: las Reales de Haarlem y Copenhague, la de Amigos naturalistas de Berlín, de Rotterdam, la Jablonowsky de Leipzig, la Económica de Dresde y de Potsdam, la de Mineralogía de Dresde y de Jena, las de Física de Frankfurt del Main, Groninga, Halle, Heidelberg, Leipzig, Marburgo y Rostock. También a las Reales Academias de San Petersburgo, Amsterdam, Berlín, Múnich y Gotinga.

La muerte, casi repentina, le sobrevino el 7 de marzo de 1824 a las diez de la noche; la tarde del viernes anterior continuaba con sus actos rutinarios, como reuniones en Sociedades científicas, e incluso expuso a mediodía del domingo su conferencia acostumbrada; horas después se sintió indispuesto.

Su amigo Hermann ha dejado inscrito en la lápida de su sepultura:

Naturae leges doctis ubicunque retectas

Cognosse impiger et tradere notitiae ${ }^{14}$.

13 Ibidem, págs. 461-462.

14 Literariamente lo está comparando con un Prometeo o Mercurio: Las leyes de la naturaleza, descubiertas por sabios de todos los lugares, / las ha conocido sin pereza para dar cuenta de ellas. 
Naturaleza y Libertad. Revista de estudios interdisciplinares. Número 1, 2012. ISSN: 2254-9668

\section{OTRAS OBRAS DE GILBERT}

La Geometría según Le Gendre, Simson, von Schwinden, Gregorio De San Vicencio y los antiguos, expuesta con su interpretación, 1798.

Una amplia colaboración para la obra editada por J.G.F. Schrader, Compendio de la teoría experimental de la Naturaleza según los nuevos descubrimientos. Para manual de lecciones académicas y para uso de los estudiantes $^{15}$. Bachmann y Gundermann, Hamburgo, 1804, 2a edición mejorada. Con cuidada xilografía.

Ensayos críticos sobre los renovados experimentos de Múnich, otra vez con el péndulo de grava sulfurada y la varilla de zahori ${ }^{16}$. 1808, en octavo y con un grabado.

Gilbert desmonta las supersticiones que hay detrás.

Publicó en la revista francesa Annales de Chimie (1809, t. LXIX, no 3, marzo: 266-267) la carta que dirigió al Instituto Nacional de París comentando los artículos de P.L. Simon, profesor de Física en la Real Escuela de Arquitectura de Berlín, consejero e inspector de las edificaciones del rey de Prusia. Refiere artículos de Simon que le había editado en sus Anales de Física: «Sobre las leyes que fundamentan la repulsión eléctrica» [(1808) t. XXVIII: 277-298], sobre la pila Volta [(1802) t. X: 282-300] y un «dispositivo galvano-químico» [(1801) t. VIII: 22-43].

15 Grundriß Experimentalnaturlehre nach den neuesten Entdeckungen. Ésta y las tres siguientes obras se citan también en Ann. (1824) t. LXXVI: 473.

16 Kritische Aufsätze über die in München wieder erneuerten Versuche mit Schwefelkiespendeln und Wünschelruthen. 
Disertacion histórico crítica sobre las razones simples y perpetuas de las mezclas quimicas cuyas leyes fueron detectadas hace tiempo ${ }^{17}$. En latín. Schwickert, Leipzig, del 21 y 25 de septiembre de 1811.

Se ocupó de Bergmann, Lavoisier, Berthollet, Proust y Richter sobre estoquiometría química. También sobre los trabajos de Berzelius.

Protocolo razonado de cómo se ha de empezar para protegerse de epidemias fibrilares de toda clase contra el contagio y la propagación de las mismas al hacer cordones sanitarios bumeantes de ácidos minerales; comprobado por una colección de experiencias en Großen ${ }^{18}$. Baumgärtner, Leipzig, 1813. En octavo. Recoge los experimentos de Guyton de Morveau.

\section{LOS REGISTER}

Dada la densidad de información y la variedad de autores, Gilbert elaboraba periódicamente unos índices donde resumía los avances en cualquiera de las áreas. Aunque la revista se llama Anales de Física, publicó investigaciones y descubrimientos que hoy irían de la Astronomía a la Fisiología, pasando por detalles de Botánica y Zoología. Predomina, por supuesto, la gran revolución antiflogista que la Química estaba haciendo. Presta atención especial a la

17 Dissertatio historico-critica de mistiorum chemicarum simplicibus et perpetuis rationibus earumque legibus nuper detectis, Sectio I et II.

18 Für jeden verständliche Anweisung, wie man es anzufangen habe, um bei bösartigen FieberEpidemien aller Art sich gegen Ansteckung zu schützen, und der Verbreitung derselben durch Mineralsäure Räucherungen Einhalt zu thun; belegt durch eine Sammlung von Erfabrungen im Großen. 
Mineralogía y a los fenómenos que empezaron llamando de galvanismo. No faltaba la riquísima correspondencia internacional, concursos de renombre, expediciones internacionales y proezas aeronáuticas.

Esta sección de la revista la subtitula «índice alfabético de materias y personas» (Alphabetisches Sach- und Namenregister). Cada entrada enviaba con una breve frase explicativa a tomo y página anterior. La gran utilidad de ordenar así la información es que permite hacer un seguimiento en el tiempo de un asunto relevante. Sucedía que cualquier artículo era un breve resumen de veintitantas páginas sobre el experimento instalado, algunas veces una especie de recensión hecha por Gilbert o colaboradores que suenan en segundo plano como una voz en off. Pero en ningún caso cerraban la cuestión, de manera que interpelaciones, nuevos matices u otras soluciones al problema aparecían en tomos siguientes, incluso años después ${ }^{19}$. Por eso resultaba más

19 Von Arnim, por ejemplo, publicó este novedoso enfoque que enorgullecía a los Naturphilosophen: «Ideen zu einer Theorie des Magneten» (Ann. (1799) t. III, págs. 48-63), al que J.W. Ritter respondió con «Algunas observaciones sobre la cohesión, y sobre la conexión de la misma con el magnetismo» («Einige Bemerkungen über die Cobäsion, und über den Zusammenhang derselben mit dem Magnetismus» en Ann. (1800) t. IV, págs. 1-33). Sólo después, la contrarréplica de von Arnim resultaba definitiva: "Ideen zu einer Theorie des Magneten (Über die Polarität)» en Ann. (1801) t. VIII, págs. 84-108. Gilbert ya había anunciado este suspense así: «No sería probablemente menos interesante para el lector que para el editor, ver cómo dos colaboradores de los Anales, cuyos conocimientos y sagacidad despiertan no escasas esperanzas, Sr. Ritter y Sr. von Arnim, simultáneamente han concebido una idea que de hecho tiene bastante en común: Independencia del magnetismo de la cohesión, y ellos sin conocer el trabajo el uno del otro». (Ann. (1800) t. IV, págs. 2-3). 
eficaz su consulta que empezar por el «índice de contenidos» (Inhalt), en primeras páginas, cuyos títulos los controlaba el propio articulista.

Otra minuciosidad como editor es que rastreaba su propia autoría cuando redactaba notas a pie de página, unas veces para presentar a un colaborador extranjero y la institución que le suscribía, otras para clarificar un tecnicismo científico, una dificultad de la traducción o una referencia bibliográfica que el autor descuidara. Estas notas, que a veces son extensas y discurren horizontalmente en dos o tres páginas, tenían una gran virtud para un lector como Hegel, pues eran comentarios que nos acercan al experto. Dedicar una entrada a un nombre propio era la mayor cortesía que podía tenerse con ese científico en activo.

Por ejemplo, al acabar 1799, añadió un índice, obviamente pequeño (15 páginas), que debía tener el valor de publicitar al suscriptor las prestaciones que la serie iba a tener. Luego otro, en 1800, con las novedades posteriores, que presentó con el subtítulo «para usar como una Historia de la Física de los años pasados» (59 páginas). En 1802, hasta el tomo XII inclusive (64 páginas). Y los años siguientes los recogió en el tomo XVIII (terminando 1804) y fue de los más extensos (95 páginas) ${ }^{20}$. E1 siguiente cuadro ilustra cómo concatenó Gilbert esas entregas:

20 Los siguientes nombres se repiten en los dos últimos registros. Descontando pasajes de la Orgánica para los que Hegel leyó manuales de anatomistas, y con excepción de Steffens que tiene entrada en el primero (Ann. (1802) t. XII: 736) pero no en el posterior, todos los citados en sus semestres de Jena están aquí: Berthollet, Biot, Brugnatelli, Cavendish, Chenevix, Dalton, Davy, Droysen, Erman, Englefield, Fourcroy, Gautherot, Gay-Lussac, Gruner, Guiglielmini, Guyton, Haüy, Heidmann, Herschel, Hermbstädt, von Humboldt, Hutton, 
Naturaleza y Libertad. Revista de estudios interdisciplinares. Número 1, 2012. ISSN: 2254-9668

\begin{tabular}{|c|c|}
\hline Año & Abarca los tomos \\
\hline 1799 & I-III \\
\hline 1800 & IV-VI \\
\hline $1801-1802$ & VII-XII \\
\hline $1803-1804$ & XIII-XVIII \\
\hline $1804-1806$ & XIX-XXIV \\
\hline
\end{tabular}

Veamos varios ejemplos. El siguiente está en todos los arranques de Hegel - un término críptico ya hoy-, no se explica en referencia a su obra ni a la de Kant. Si no sale uno de su especulación, terminaría creyendo que el éter es un término metafísico que funda todo lo demás.

Éter [Aether], evaporación del mismo y elasticidad de su vapor, [t.] XV: 14, 37, 137. Expansibilidad del mismo, [t.] XIV, [p.] 280, un curioso comportamiento al evaporar[, t.] XIII, [p.] $100^{21}$.

Otro término para la polémica es «afinidad» (Verwandtschaft), enriquecida con varias notas de Gilbert — añade la letra $a$-:

Jäger, Lambert, De Lüc, Maréchaux, van Marum, Mitchill, Nicholson, Pfaff, Ritter, Richter, Robertson, von Rumford, Sage, G.G. Schmidt, Thenard, Vassalli, Vauquelin, Volta y Winterl.

21 Ann. (1804) t. XVIII: 439-440. 
Afinidad, química, [t.] XIII: 98, 100, 158a, 207a, [t.] XV, [p.] 525 $a^{22}$.

Ahora un autor que Hegel leyó y citó con precisión:

Dalton. (XIII, 265) Otras deliberaciones de su nueva teoría sobre la constitución de la mezcla de gases, [t.] XIII, [p.] 438. [t.] XIV, [p.] 95 a (Observaciones sobre esta hipótesis suya, [t.] XV: 24, 50, 123. [t.] XVI: 93). Ensayo sobre calor y frío que resulta por comprensión mecánica y rarefacción del aire, [t.] XIV, [p.] 101. Sobre la fuerza de los fluidos de conducir el calor, [p.] 184. Sobre el punto cero absoluto [absoluten Nullpunkt] del calor y consideraciones semejantes, [p.] 237. Ensayo sobre la dilatación del agua por el calor, [p.] $293[\ldots]^{23}$.

Gilbert escribe así «absoluto», pero apenas le sale si no es a propósito de Dalton y para referirse a fenómenos de cambio de temperaturas. Dalton utiliza mucho el término inglés absolute como adjetivo, siempre que se refiere al límite final de una escala matematizada. Y Hegel imita ese matiz que percibía como un estilo de la educación británica. Fuera del laboratorio, cualquiera podía aceptar también el significado de límite extremo más allá de la experiencia posible. Ese era el estado de la cuestión y esa fue la voz que debió leer en los Register cuando Hegel no podía redactar otra cosa sino:

La compresión de la fluidez elástica en una máquina compresora muestra calentamiento; [...] La rarefacción de la fluidez expansible en la bomba de aire produce enfriamiento, pues la temperatura presente se hace latente, aplicándose a la existencia, a la extensión ${ }^{24}$.

22 Ibidem: 525.

23 Ann. (1804) t. XVIII: 450.

24 HGW 8: 64. 
Hegel utiliza aquí el término «existencia» sin ninguna impregnación de la Teodicea. Ante la rivalidad que se vivía en Francia entre cartesianos y newtonianos, Hegel se inclinó por el cartesianismo. Entiende este término como tomar un espacio. $\mathrm{Y}$ ahora añade una cualidad que ni es geométrica ni es ponderable: encerrar un calor dentro de sí también es «existir». $\mathrm{Y}$ en los límites con la nada concibe frío.

Las referencias de Gilbert a Dalton siguen así durante más de media página. Eso sin considerar alusiones cruzadas a él en otras entradas, por ejemplo dentro del término "gas». Tal peso tipográfico sólo lo exhiben en estos años Davy, von Rumford (conde de), von Humboldt, Parrot y Ritter. Y, por supuesto, la vanidad excusable de página entera de Gilbert para sí mismo:

Veneno [Gift] [t.] XVI, [p.] 399

Gilbert, Sobre los viajes aéreos del ciudadano Garnerin y Robertson, [t.] XVI, [págs.] 1, $164,257[\ldots]$

Girard, Aparato de Woulf mejorado por [t.] XIII, [p.] $284^{25}$.

En alguna ocasión, no tenía más remedio para resumir la materia que hacer una pregunta breve.

Abrevio con HGW la edición crítica de la obra de Hegel, Gesammelte Werke. Meiner, Hamburgo, 1968, 1971 y 1976, años correspondientes a los tomos 4, 6 y 8. De este último tomo hay traducción (por Ripalda): Hegel, Filosofía Real. FCE, Madrid, ${ }^{2} 2006$.

25 Ann. (1804) t. XVIII: 480-481. 
Naturaleza y Libertad. Revista de estudios interdisciplinares. Número 1, 2012. ISSN: 2254-9668

Grimm, J.K.P., algunos ensayos con la pila Volta; que la electricidad incrementa la disolución animal; jes el agua un no-conductor del calor? [t.] VII, [p.] 348 [... ${ }^{26}$.

O ésta que apela a la autoridad de alguien que Hegel conocía bien cuando se habilitó con el De Orbitis planetarum, Olbers, que es el descubridor de los asteroides Ceres y Pallas, una franja orbital que descuidó en su disertación. En la entrada «Benzenberg», astrónomo de Hamburgo, dice:

Escrito al Dr. Olbers en Bremen sobre la pregunta: ¿'Son las estrellas fugaces de origen telúrico o cósmico? [t.] XIV, [p.] $46^{27}$.

Así que Hegel al comienzo de la Realphilosophie escribe entre la duda:

«...lo mismo que todas las ideas de lo que se llama explicar la génesis: si los cometas se han desprendido del Sol, si son vapores atmosféricos, etc. ${ }^{28}$.

\section{GILBERT TRADUCE A CHENEVIX}

Hasta tal punto la visita que nos interesa hizo estallar tantas cosas y se cruzaron tantos ataques, que podemos afirmar que la relación entre la $\mathrm{Na}$ turphilosophie y los Anales de Física marcó para siempre un antes y un después.

26 Ann. (1802) t. XII: 707.

27 Ann. (1804) t. XVIII: 443.

28 HGW 8: 29. 
Richard Chenevix viajó a Alemania, y Jena no se libró. Este inglés, experto en el cobre de Cornwall, conocía bien la explotación minera de las islas británicas e inspeccionaba el control de pureza en la acuñación de moneda ${ }^{29}$.

$\mathrm{Al}$ margen de su sonada rectificación sobre el magnetismo del níquel y su artículo en los Anales sobre ácidos (revisado por Berthollet ${ }^{30}$ ), Chenevix intervino sobre todo para rebatir los libros de Winterl, una de las fuentes más apreciadas por Hegel. Más allá del exotismo de dirigir el botánico de Budapest, Hegel adoptó de Winterl todo aquello por lo que él venía apostando para cohesionar el Sistema de la Ciencia, contorsionó todas las áreas experimentales viéndolas como un solo proceso de una triple figura lógica. Winterl había encontrado antes los principios de la Química, considerándolos como una regla silogística con dos términos opuestos y su término medio ${ }^{31}$. La publicidad que de Winterl hicieron Guyton desde París y el traductor de

29 Humphry Davy — muy receptivo al romanticismo-, que escuchó las charlas del poeta Coleridge a su vuelta de Prusia oriental y colaboró con Dalton en la Lit and Phil, también viajó a Alemania.

30 R. Chenevix (miembro de la Royal Society): «Versuche über die Bestandtheile der Schwefelsäure und schwefelsaurer Salze. Mit Bemerkungen von Berthollet (Ensayo sobre los componentes del ácido sulfúrico y sulfatos. Con observaciones de Berthollet)» en Ann. (1803) t. XIII: 166.

$31 \mathrm{Vid}$. HGW 8: 107 (nota 4). La tesis básica de Winterl es que la materia es de suyo inerte, y sólo se hace activa por la intervención de «dos principios» ajenos y recíprocamente contrapuestos (principium aciditatis et principium basicitatis), y que estos principios se combinan con la materia gracias a una «sustancia mediadora». Consideraba al agua constituida de hidrógeno («principium animans» de las bases y con electricidad negativa) y oxígeno (principio ácido y con electricidad positiva); justo los hechos que Ritter confirmó detalladamente con la pila Volta de Jena. 
Winterl al alemán, era conocida. Gilbert se hizo eco varias veces ${ }^{32}$. El traductor era Schuster, y la edición salió en Jena por el empeño del librero Frommann, muy amigo de Hegel.

Esta visita marcó los semestres de Naturphilosophie de Hegel en la universidad de Jena, y muchos giros que pueden pasar por el más puro lenguaje de la especulación son en realidad refutaciones a las duras palabras que había oído de Chenevix. Una explosión tal condicionó para siempre su relación con Schelling. Fue un ataque contra todo su círculo.

En el semestre 1803/04, Hegel menciona explícitamente a Chenevix a propósito de unos óxidos de cobre y de fósforo ${ }^{33}$, después de una cita literal de la Quimica estática de Berthollet y tras unas consideraciones sobre afinidades; casualmente, es la misma confrontación que publica Gilbert ${ }^{34}$. En la Realphilosophie, Hegel ni lo nombra, pero le descarga su argumentario con más energía, y ello porque Gilbert fue traduciendo las intervenciones y réplicas de Chenevix hasta dos años después. Chenevix estuvo en Jena en 1803, durante el verano en que Hegel redactó el primer manuscrito de Naturphilosophie para las clases del semestre de invierno de 1803/04. Después, en el semestre de 1805/06, todo es ya recuerdo. En la segunda entrega de los Ana-

32 Guyton de Morveau: «Beurtheilung von Winterl's Chemie des 19ten Jahrbunderts» en Ann. (1803) t. XV: 497. La obra de Winterl en cuestión era Prolusiones ad chemiam saeculi decimi noni (Budapest, 1800), que se reeditó en 1803 con unos añadidos (Accesiones novae). Parte de su obra la tradujo al alemán Schuster: Darstellung der vier Bestandtheile der anorganischer Natur. Eine Umarbeitung der ersten Theiles seiner Prolusiones und Accesiones (1804).

33 HGW 6: 163.

34 Ann. (1803) t. XIII: 166. 
les de Física de 1805 —antes del verano-, en una batería de tres artículos que Gilbert casi disimula detrás de largos titulares, Chenevix sigue sin dejar títere con cabeza. Uno le debió impresionar a Hegel, porque desautorizaba a un discreto y diligente Ørsted, que él ya había leído con interés y al que había dedicado unas páginas en la Revista crítica de Filosofía a dúo con Schelling ${ }^{35}$ :

Observaciones sobre un trabajo que se encabeza con el título: Materiales para una Química del siglo XIX, editado por el Dr. J.B. Ørsted, Regensburg, 1803; por el Sr. Chenevix, miembro de la Sociedad londinense, de la Academia irlandesa, etc. ${ }^{36}$.

Detrás de ese título estaba la recopilación de los textos de Winterl. Chenevix sabe que Guyton de Morveau ${ }^{37}$ había reconocido su interés por este libro del húngaro. Ørsted, en el prólogo, indica que el sistema de Lavoisier no estaba completo. Chenevix lo repite con ironía. Y es que no contestaba a preguntas como “ipor qué se saturan ácidos y bases?”, “¿cuál es el principio general de los metales?”. Chenevix cita al propio Ørsted:

35 Hegel le hizo una recensión en el Kritisches Journal, t. II, parte $3^{\text {a }}$, a las Ideen zu einer neuen Architektonik der Naturmetaphysik de J. Ørsted, impreso por M.H. Mendel, Berlín, 1802. HGW 4: 494-496.

36 «Bemerkungen über ein Werk, welches den Titel fübrt: Materialien zu einer Chemie des neunzehten Jahrhunderts...» (Obsérvese la dilación de Gilbert en publicarlo, pues el artículo se había dado a conocer en los Annales de Chimie en mayo de 1804, t. L, págs. 173-199 y en los Philosophical Transactions de la Royal Society) en Ann. (1805) t. XX, págs. 422-454.

37 «Guyton's Beurtheilung von Winterl's Chemie des 19ten Jabrbunderts» en Ann. (1803) t. XV: 496. 
Mientras Lavoisier hilvanó con su visión sólo una pequeña porción de la ciencia, el Sr. Winterl ha abarcado el universo en su visión. Es uno de esos extraños hombres que siguen con ojos abiertos cada expresión curiosa de la Naturaleza hasta entenderla. No va de una experiencia a otra, sino de una experiencia a la Naturaleza toda. En los cimientos que acostumbran los químicos a abandonar, después de que hayan preparado sus reactivos, ha encontrado ese espíritu penetrante de la materia que nos resuelve el secreto de la mezcla de metales, las tierras, las bases, los tipos de aires, etc. El profesor de Pest es mucho más observador que experimentador ${ }^{38}$.

El sentido de términos como «sistema», «la Naturaleza toda», observación, etc., es el mismo inequívocamente que Hegel ejercita en su obra en ciernes. En su artículo, Chenevix hace citas largas de Winterl; con breves pinceladas se sorprende y las refuta:

\section{Del principio ácido:}

Hay un principio de la acidez y un principio de la alcalinidad o de la basicidad. Ambos son fuerzas contrapuestas, que se superan $\left[\right.$ aufheben ${ }^{39}$ ] según proporciones conocidas. Si se descompone una sal que tiene un principio fluido en algo de calor que sea mínimo, como es el calor incandescente, entonces se separa el principio fluido (sea ácido o alcalino) en un estado embotado, y ha perdido todos sus caracteres. Por ejemplo, el ácido sulfuroso de potasa; $[\ldots]$

Y Hegel en su semestre de 1803/04 explicaba:

38 Para ésta y la siguiente cita: Ann. (1805) t. XX, págs. 422-424.

39 Schuster, que traduce del latín académico de Winterl, no opta por este término copiándoselo a Hegel; es Hegel quien lo copia de ellos tomando ese sentido de resultado de una reacción química o su "neutralización". 
c) Los ácidos y bases están tan embotados como disponibles en la neutralidad de exponerse separados también, $[\ldots]^{40}$.

La dicotomía embotados o despuntados referida a una disolución la seguirá utilizando por analogía Hegel en su Lógica ${ }^{41}$.

Otro ejemplo:

Sobre la andronia ${ }^{42}$ :

En todos los reinos de la Naturaleza se encuentra una sustancia que era hasta ahora desconocida. Es $\left(1^{\circ}\right)$ ácida y se conecta con todas las bases, no sólo con amoniaco. Es $\left(2^{\circ}\right)$ resistente al fuego si no está en contacto ni con aire vital [oxígeno] ni con algún ácido. (3॰) Entra en sinsomatía con los ácidos (una palabra que el Sr. Winterl propone para la conexión de dos materias de igual naturaleza, por ejemplo dos ácidos o dos bases uno con otro) [...] y da con un poco de aire vital nitrógeno, con más aire vital y principio ácido, gas dióxido de carbono, y con mucho más de ambos ácido nítrico. Forma (4) con hidrógeno las materias que constituyen el más grande componente de los cuerpos orgánicos, leche, clara de huevo, etc. ${ }^{43}$.

\section{HGW 6: 168}

41 Cfr. Ciencia de la Lógica. $2^{a}$ parte (trad. de Augusta y Rodolfo Mondolfo). Ediciones Solar, Buenos Aires, 1982: 440 \{correspondiente a Wissenschaft der Logik II en Werke in zwanzig Bänden, 6 (eds. Moldenhauer y M. Michel). Suhrkamp, Frankfurt del Main, 1969-1979: 431\}.

42 Los experimentos de Steffens suponen esta hipótesis de la andronia cuando habla del «amoniaco corrosivo» (ätzendes Ammoniak) en Ann. (1801) t. VII: 524. Páginas antes Winterl se había pronunciado «contra la nueva Química». Idem. p. 380.

43 Para ésta y la anterior referencia en la que Chenevix cita a Winterl: Ann. (1805) t. XX, págs. 424-431. 
El texto de Winterl que entrecomilla Chenevix Hegel también lo tenía leído ya desde 1803/04 como atestigua este pasaje:

...no encontramos este sentido cuando se hace del nitrógeno, etc., principios absolutos y esencias de lo orgánico; por ejemplo, se ha tomado lo vegetal como el dominio del carbono, y lo animal como dominio del nitrógeno, lo que, como se ve por lo ya dicho, incluso tomado del todo empíricamente de los productos, no es verdad. La andronia, el nitrógeno, se darían tanto en lo vegetal como en lo orgánico, lo que da a todo eso un sentido completamente burdo, como si ciertos elementos tuvieran algo de substancial ${ }^{44}$.

En el añadido al § 327 de la Enciclopedia, Hegel vuelve a citarlo. Petry deja tal cual synsomation en su versión inglesa. En el texto principal del parágrafo, Hegel dice: «Este tipo de unión de cuerpos sin actividad química respectiva se da en la amalgama y otras aleaciones de metales, mezclas de ácidos de alcohol con agua y otras parecidas».

La segunda embestida de Chenevix fue contra Christian Samuel Wei $\beta$, que era el traductor de Haüy en Alemania y referencia obligada en la Escuela de Minas de Freiberg; además, el Consejo de Minas de Prusia le tenía bien considerado.

Tanto la Cristalografía como la Química tenían una repercusión grande sobre las conciencias. Cualquier pieza que se desplazara a esta altura iba a mover en su desfase todo el Sistema. Una ciencia naciente modifica la visión del mundo y hace saltar la educación y las ideologías anquilosadas. La metodología de Winterl fue ante todo la de un científico, de tal modo que la 
experimentación de un detalle no lleva a otro detalle, sino a la Naturaleza como conjunto; no de cromo a colección — como se deleita el empirista-, sino que él se plantea el relato completo. Finalidad y necesidad siguen siendo aspectos distintos cuando se aplican a la Naturaleza; cuando se postulan principios, proporción y comportamientos de los reactivos, o una determinada combinación de afinidades, lo que hay implícito es un plan de la Naturaleza. Winterl no deduce una inteligencia ordenadora, pero Hegel sí. Sobre ella se preguntará en el primer párrafo de la Filosofía del Espiritu, es decir, lo que viene a continuación de la Filosofía de la Naturaleza; a las dos juntas las llama la Realphilosophie, y constituyen los dos grandes pilares de su «Sistema de la Ciencia». El gabinete del químico refleja, pues, un plan de la materia que se concluye por Lógica, al menos para Winterl y para Hegel.

El hecho de que existan fuerzas de atracción y repulsión en la materia, hacía repensar que quizá tuviera sentido entender qué es «creación a partir de la nada». Y con esto también si ese «barro» que tomó Dios es verdad que tiene ese matiz exegético de maldito, de materia de condenación.

Chenevix cita ahora de Wei $\beta$ :

10) Hay en la Naturaleza no meramente una atracción química, sino también una repulsión química, mediante la cual los cuerpos se disuelven entre heterogéneos tratando de desunirse o partirse. La Naturaleza entera es un mero despliegue de magnitudes positivas y negativas, desde el cero o la nada. Ninguna materia hace arrogarse una existencia absoluta; cada una no es otra cosa sino una magnitud, un polo que tiene que agradecer su 
Ese «sino también» de la primera línea era un no aceptar desesperado del que no se movieron los Naturphilosophen- de los descubrimientos de Dalton sobre el vacío, el atomismo y la mezcla de gases, que Hegel había citado como una línea roja para sí mismo. Lo demás tiene mucho de nostalgia (de los errores) de Kant, al que menciona por cierto Chenevix: «Kant y Schelling pegados [accollés]» —dice líneas antes de este pasaje de Wei $\beta$ que cita y transcribe-

Y respecto a las líneas finales, como antes al referirnos a Winterl, es Hegel quien mimetiza de los físicos de su época la dialecticidad de la materia. La dialecticidad como lo propio de aquello que está destinado a la nada.

\section{6. «...GILBERT, LÍBRAME DE SCHELLING»}

«No hay nada en la Lógica que pueda cambiar el mundo» ${ }^{46}$. Esta afirmación — que tan familiar resulta - no es de quien podía pensarse, ni sale de aquella lápida que presidía la universidad von Humboldt. Procede de quien sobre la obra de Hegel prestó atención al paso deductivo de la Lógica a la Naturaleza. Después de él casi nadie abordó este tema, casi todos lo recha-

45 R. Chenevix: «Bemerkungen, veranlaßt durch einen Aufsatz des Dr. Ch.S. Weiß, der in der deutschen Übersetzung von Haüy's Mineralogie durch D.L.G. Karsten, kön. preuß. Geh. Oberbergrath, abgedruckt ist» en Ann. (1805) t. XX: 456.

46 Pertenece a las clases que Schelling desarrolló en la Universidad de Múnich en 1827: Werke (ed. Schröter, Múnich, 1927/1954) vol. 5: 223. 
zaron, con la única excepción de Michelet, responsable de la reedición póstuma de la Enciclopedia, cuyo prefacio comenzaba con la valiente expresión «filosofar sobre la Naturaleza es crear Naturaleza». La posición de Michelet es fiel a Hegel, pues ambos consideran que la tarea de la $\mathrm{Na}$ turphilosophie de comprender la Naturaleza sólo mediante conceptos es «idílica y utópica». Exactamente como cita de un amigo común, Link, director del botánico de Berlín, que, a propósito de unos "fisiofilósofos", decía: «la especulación de ese tipo no puede sino ofrecer vagas relaciones y superficialidades, nunca aborda la inextinguible profusión de lo actual, y en lugar de interpretar el mundo actual, nos ofrece jeroglíficos».

El significado de la anterior afirmación de Schelling desciende de aquel fondo común del seminario luterano de Tubinga, de Jakob Böhme: «la libertad divina se vomita a sí misma en la Naturaleza»; este exceso que se remonta a la omnipotente voluntad de Dios, le sugiere a Hegel la acuñación metafísica más extraña: «la idea divina anticipa naturaleza». Este eco que implícitamente reverbera en la escritura de Hegel es lo que nutrió el método de M.J. Petry, quien fue rescatando en la década de los 70 las fuentes de Hegel.

Schelling se pronuncia sobre un Hegel más tardío que las lechuzas; y cuanto más abundara Hegel, tanto más le verían como sombra de Schelling. Pese a ese silencio, Hegel siempre estuvo a vueltas con la Naturphilosophie de una manera propia, y cuando la Forschungsgemeinschaft acabe la edición crítica de las obras de Hegel, se verá que ésta le ocupó más de un tercio de su obra. En aquellas lecciones de Múnich de 1827, Schelling decía que «Hegel 
ha intentado erigir su lógica abstracta por encima de la Naturphilosophie. Sin embargo, ha incorporado dentro de ella el método de la Naturphilosophie» ${ }^{47}$. Schelling y Hegel compartían de Fichte la distinción entre intuición intelectual y pensamiento racional. En el $\S 7$ de la Enciclopedia dice que el reflexionar contiene «el principio de la Filosofía», pero que éste ha rebrotado en los tiempos modernos — después de la reforma luterana, le gusta a Hegel destacar-, y a diferencia de los orígenes jonios, no se ha sostenido «de manera meramente abstracta», sino "dentro del océano de las singularidades empíricas». Se refiere claramente a la Física experimental. Es decir, la Filosofía ha tomado «su contenido de la naturaleza presente, e igualmente del espíritu presente». Lo de presente resulta inquietante.

Al empezar la segunda parte, la Naturphilosophie, en el § 246, vuelve a recordarlo: «La filosofía no solamente ha de concordar con la experiencia de la Naturaleza, sino que el origen y formación de la ciencia filosófica tiene a la Física empírica como supuesto y condición ${ }^{48}$. Pocas líneas después, precavida e implícitamente, niega a Schelling por segunda vez: «Menos procedente es aún una apelación a lo que se llama intuición y que no suele ser otra cosa que un enredarse con la representación y la fantasía (incluso la fantasmagoría)». Ese «lo que se llama», dicho con ese estilo, es un claro golpe a Schelling. La Naturaleza era vista por Schelling como la producción inconsciente del Yo, como natura naturans; se plantea como una alteridad a superar

47 Werke, 1927, op. cit.: 208.

48 G.W.F. Hegel: Enciclopedia de las Ciencias filosóficas (trad. Valls Plana). Alianza, Madrid, 1999: 305 . 
por la titánica autoafirmación moral del Yo. La intuición venía a ser la acción originaria: el modo como el Yo se capta a sí mismo como Yo.

De este destino del idealismo jenense no pudo escapar Hegel nunca, es decir, del hueco dejado por Fichte y su influencia en el romanticismo, de la cercanía de Schelling y la necesidad de autoafirmarse contra él. Pero sí podía consultar los Annalen der Physik ${ }^{49}$ como actas de la declaración más fidedigna de la Naturaleza. Es decir, como la otra Física, la que se basa en experimentos y no en intuiciones, la que instruye datos empíricos al modo de la casuística procesal británica y baconiana, que es como reunía Gilbert artículo tras artículo sus Annalen der Physik, y como enciclopédicamente confeccionaba sus Register. Esta revista por entregas, merced a la labor de edición de Gilbert, facilitó a Hegel la tarea de extractar información científica; después la interpretaba especulativamente. Si los saberes científicos quedan ordenados por la Filosofía de manera holística, es porque comparten siempre un mismo objeto: la Naturaleza. O bien el planeta Tierra, que emerge ahora como nueva tópica del saber.

En 1801, Gilbert había reunido providencialmente a media Escuela de Schelling: Ritter, Steffens y Pfaff, también a Winterl, casi un asimilado de la Naturphilosophie. Ritter optimizó la pila Volta de Jena mejor que nadie, una cara inversión del duque de Sajonia para una universidad ya decrépita. Y seguidamente demostró que la invisible electricidad tenía un fundamento

49 Dedico mi tesis a la influencia de esta obra colectiva y por entregas en los primeros semestres de Hegel en la universidad de Jena (1803-1806): De la Naturphilosophie al Sistema de la Ciencia, UNED, Madrid, 2010. 
químico $^{50}$, pues descubre que el oxígeno aporta la carga positiva $(+)$ y el hidrógeno la negativa (-).

Con esta polaridad, Hegel concibe también la noción de fuerza y su dialecticidad como la pulsión implícita de la Naturaleza, pero de una manera menos oscurantista que Schelling. Steffens, doctorando de Schelling, electroliza disoluciones nitrogenadas ${ }^{51}$, discute a Humphry Davy y asocia al tejido nervioso elementos químicos distintos al muscular. En este contexto, rehabilitaron la obra de Brown Elements of Medicine ${ }^{52}$, que había explicado la enfermedad como un desajuste psíquico, y el cuerpo como un «sistema de irritabilidad» ante estímulos tanto externos como internos. Hegel incorpora esa noción y desmitifica a la vez la «fuerza vital» (Lebenskraft) del romanticismo. Tenemos, entonces, una dinámica basada a fin de cuentas en ácidos y álcalis, en un quimismo del oxígeno o del hidrógeno. Desde aquí Berthollet desbancó la teoría de las afinidades electivas ${ }^{53}$, tan defendidas por las universidades alemanas y elevadas a visión omnicomprensiva por Goethe; Gilbert divulgó entonces en los Anales a Berthollet y a todo su equipo de la

50 J.W. Ritter: «Versuche zum Beweise, daß auch bei der gewöhnlichen Electricität, in chemischer Hinsicht, die positive die oxigène hingegen die hydrogene sey» en Ann. (1801) t. IX: 1-17. 51 «Auszüge aus Briefen an den Herausgeber. [...] 4. Von Heinrik Steffens in Freiberg (Versuche mit Volta's Säule, besonders über die Zersetzung des Ammoniaks)» en Ann. (1801) t. VII: 523-524.

52 Que era la tesis doctoral que presentó en 1780 a la facultad de Medicina de Edimburgo (Elementae medicinae), y que precisamente tradujo C.H Pfaff, amigo de Schelling y Ritter, como System der Heilkunde.

53 Vigente desde la publicación de impacto del sueco Tobern Olaf Bergmann Disquisitio de attractionibus electivis (1775), que rectificaba las tablas de Geoffroy, guía de la práctica de laboratorio durante el siglo anterior. 
École Polytechnique, que sirvieron así de cabeza de puente a la influencia francesa. Hegel siguió también el manual en dos volúmenes de Berthollet Essai de Chimie statique (Didot, París, 1803); pero el impacto de tal obra no se podía desligar del trabajo de Fischer como traductor, que anunció la publicación en la revista de Gilbert ${ }^{54}$. Gilbert superaba así la agria polémica de sus primeros años por decantarse tan claramente por la Química antiflogística. Como editor, tuvo que hacerse eco de la polémica de De Lüc y Lichtenberg sobre esos mismos gases, pero en la atmósfera; con la «teoría de la lluvia» de Lichtenberg había jugado el flogisto su última baza. Hegel cita en su semestre de invierno de 1803/04 a «De Lüc y Lichtenberg" ${ }^{55}$, así tal cual como los alineó Gilbert; también sigue a «Prévost» sobre «el rocío» ${ }^{56}$ y la penetrabilidad de la materia por esas formas gaseosas. Todo esto prueba que Hegel estuvo muy atento a estos cambios científicos y a la defensa que Gilbert hizo de los mismos. La sustancia deja de ser lo permanente e inalterable que accidentalmente se mezcla y se muestra como dos fuerzas imponderables opuestas, en las que un extremo transforma al otro o lo anula, y él mismo queda transformado. Hegel reinventa así la Lógica concibiendo el pensamiento como otra suerte de movimiento, a imitación del proceso que dos reactivos hacen en una disolución: de extremo universal a particular, o bien de particular a singular; es la dinamicidad del pensamiento como dialéctica,

54 E.G. Fischer ya había traducido de Berthollet Recherches sur les lois de l'affinité, Mémoires de l'Institut National, París, 1800-1801. La traducción salió en Nauck (Berlín, 1802), y Gilbert la divulgó en su revista: Ann. (1803) t. XIII: 158-159.

55 HGW 6: 96.

56 Infra. n. 66 
para la que Hegel se ha inspirado en los cambios internos de la Naturaleza. El pensamiento salta de fase - de universal a particular, por ejemplo- y pivota sobre un término medio. Ahora bien, ese término neutro era el "agua" del quimismo —ácido y base sus extremos-. Tal silogística atraviesa todo el Sistema.

Cuando en el verano de 1831, en Potsdam, Hegel retocaba una vez más la gran Lógica, vuelve a citar a Ritter, Fischer y Berthollet. Es como si en la memoria de una biografía se acumulara una segunda nostalgia, y ésta remitía sin duda a sus inicios como profesor en Jena, cuando explicaba Naturphilosophie y redactaba la Fenomenología del Espiritu.

\section{QUIMISMO CONTRA LÓGICA}

Muchos científicos escribieron por entonces "filosofías de la Química"; entre los ejemplos más reconocidos están La philosophie chimique de Fourcroy y A new system of chemical philosophy de Dalton, 1792 y 1808 respectivamente. Ambos autores son citados por Hegel. La cuestión no se decidía en un supuesto diálogo entre Filosofía y ciencias experimentales, como pudiera pensarse hoy; más bien era la Química la que pugnaba por obtener un puesto digno en las instituciones académicas, encorsetada hasta entonces como un saber auxiliar dentro de las facultades de Medicina y supeditada a las hipótesis de la física newtoniana. Piénsese que Humphry Davy, descubridor de varios elementos, profesor de la Institución Real de Londres protegida por von Rumford, y después presidente de la Royal Society, tuvo una formación completamente práctica como aprendiz de farmacéutico sin hacer tan siquiera bachillerato. Así que fue la elaboración de una química teórica, que 
expurga de la Química áreas intrusas, lo que llamó la atención de los filósofos de la Naturaleza (Naturphilosophen). El quimismo, en cualquier caso, representó para Hegel la piedra angular del "Sistema de la Ciencia". Esa aspiración de nuevo estatuto científico la formuló muy bien para su época Trommsdorff, que hablaba de una Chemie a priori o una reine Chemie ${ }^{57}$.

A Richter le hubiera bastado con la matemática ${ }^{58}$, habida cuenta de que siempre se da una proporción estricta antes y después de cualquier reacción, pero se trataba de algo más. La iniciativa la había llevado Lavoisier desde 1780, y la situación irreversible es la que él había determinado como química antiflogista. La posición contraria defendía la existencia del flogisto, y remontaba su prestigio a Becher y Stahl, pero tenía entre sus últimos defensores a Kirwan, Priestley, y a Gren en Alemania. Stahl postuló esa teoría que hacía descansar la combustibilidad en el azufre, al igual que los alquimistas. Creía que los minerales fósiles y oleosos eran los que más flogisto contenían; al quemarse, liberaban su flogisto despidiendo calor y luz. Pero las cosas empezaron a cambiar cuando Lavoisier calcinó algunos metales, y observó que en lugar de perder peso, como podía esperarse, lo ganaban. En cuanto Pristley le contó que había aislado un nuevo elemento, al que llamaba «aire deflogistizado» - es decir, el futuro oxígeno-, Lavoisier se dio cuenta enseguida de la importancia del hallazgo, pues ese gas era justo lo que sus metales absorbían al calentarlos, por eso el aumento de peso. Esto signifi- 
caba que la quema era en realidad una reacción del combustible con el oxígeno del aire, y no que el combustible soltara algo suyo al aire.

La oposición entre química flogística y antiflogística, sin embargo, es más insignificante de lo que ha amplificado luego la historia de la ciencia ${ }^{59}$. Las dos tienen carencias comunes que la Química del XIX irá venciendo, pero ambas orientaciones parten de un concepto de "elemento", según el cual luz y calor son elementos químicos, y no reconocen que sales y álcalis representen conexiones. La Química antiflogística, además, exagera la importancia del oxígeno e inicia un abandono de la doctrina de la atracción, a cuya investigación se dedicaron sobre todo flogistas, Bergmann y Richter, por ejemplo, y más tarde antiflogistas como Berthollet y Proust.

Priestley, que en buena medida es el descubridor del oxígeno junto a Scheele, paradójicamente siguió llamándolo «aire deflogistizado». Expresiones así de caducas se deslizaban también en la revista. Dudas como las de Priestley eran similares a las de otros investigadores, por ejemplo De Lüc y Mayer en la primera entrega de 1800. Así que durante varios años Gilbert tuvo que hacer equilibrios en su edición para no enfadar a unos y otros. Aún así, Kries, albacea de los póstumos de Lichtenberg, lanzó algún improperio contra Gilbert ${ }^{60}$.

Hablar de elemento en un sentido absoluto es absurdo, según Lavoisier; es algo «puramente metafísico», sin ninguna posibilidad de comprobación

59 Von Engelhardt, D.: Hegel und die Chemie. Guido Pressler, Wiesbaden, 1976: 88.

60 «Auszüge aus andern Briefen an den Herausgeber: 1. Vom Herrn Prof. Kries in Gotha (Lichtenberg's Hygrometrie, hinterlaßene Schriften, Biographie)» en Ann. (1800) t. IV: 126. Contra Kries polemizaron en los Anales Zylius y Mayer (Ann. (1800) t. V: 263). 
empírica. Ahora bien, este escepticismo sobre los elementos no lo aplicaron al oxígeno, que se presenta siempre bajo numerosos enlaces, incluso diverso cuando es consigo mismo. De la misma manera se relativizó la noción de enlace o conexión química. Los enlaces químicos responden a materias que se descomponen y nuevamente se dejan sintetizar ganando otros ingredientes. Composición y descomposición se convirtieron entonces en la prueba infalible, hasta el punto que Lavoisier llega a afirmar que no nos podemos sentir plenamente satisfechos hasta que no reunamos a las dos como prueba $^{61}$. Esta exigencia pronto actuó en todos los laboratorios como un factor de progreso. Por ejemplo, ante todo el debate sobre el aristotélico y unitario elemento agua, que se había visto separado por electrólisis en sus ingredientes gaseosos oxígeno e hidrógeno, se silenció de golpe a probables incrédulos cuando Cavendish en un eudímetro volvió a sintetizar agua al inflamar hidrógeno con una chispa eléctrica ${ }^{62}$. En sus inicios como editor, Gilbert da la impresión de que quisiera dar voz a un Lavoisier muerto antes de culminar su carrera — fue guillotinado en 1794-. Entre los resultados ventajosos del nuevo planteamiento antiflogista, estuvo el considerar elementos a los metales, es decir, no enlaces de cal y flogisto. Desde luego, los

61 Traité elementaire de Chimie, 1789: 7-8.

$62 \mathrm{El}$ experimento lo logró Cavendish en la Royal Society, en 1781, pero Gilbert, tantos años después, seguía atento a sus últimos trabajos: «Versuche, um die Dichtigkeit der Erde zu bestimmen» en Ann. (1799) t. II, págs. 1-62. Es decir, Gilbert, ante el primer tomo que prácticamente ya confecciona él sólo, porque el anterior todavía lo había dejado indicado Gren, pone a Cavendish en portada como su nueva carta de presentación. El artículo está directamente explicado por Gilbert, y tenía un impacto definitivo para estudios de Geodesia y Mineralogía. 
Anales de Física se convirtieron en las actas de registro de los nuevos metales descubiertos. Sin embargo, algo quedaba inamovible antes y después del dominio antiflogista, como era la consideración de los imponderables luz y calor ${ }^{63}$.

Pero Gren ya había observado un cierto repliegue táctico en otros flogistas. Erxleben, célebre por su manual Anfangsgründe der Chemie (Gotinga, 1775), reconocía la importancia del aire —o algo del aire— en la combustión, en lugar de considerar que una sustancia combustible (flogisto) se escapara de la materia quemada. Y sobre lo que era la prueba incontrovertible del debate, el aumento de peso del metal calcinado, decía:

La calcinación de los metales por el fuego supone sin excepción el paso continuo de aire. [...]. En un recipiente cerrado con aire, sólo se puede calcinar exactamente una determinada cantidad de metal; si esto sucede, entonces el metal termina también por calcinarse con el calor más grande, así como el aire deja también de disminuir ${ }^{64}$.

E incluso desde las filas de los flogistas ya se lanzó la hipótesis de que el aumento de peso del metal calcinado pudiera deberse a un aire comprimido

63 Hegel sigue siendo flogista en sus explicaciones sobre este punto, y seguramente se confía todavía al manual de Gren. Sólo que en 1805/06, en la Realphilosophie, es ya una posición muy retrógrada. El metal — dice Hegel— «conserva su luz y sólo cambia de colores», «pertenece simplemente a la luz», «no se descompone en los extremos base y ácido». (HGW 8, págs. 8990 (págs. 76-77)). 64 Op. cit.: 436. 
que se alojaba en los poros del metal ${ }^{65}$. Así que atender a la porosidad de la materia sólida, su aparente compacidad y cohesión, era la última vía de investigación que le quedaba a los flogistas; por eso el comportamiento de mezclas de gases no sólo abría un campo muy fructífero, sino que se convertiría en una prueba decisiva. Gilbert, que lo supo ver, reunió y tradujo para los alemanes las investigaciones de Prévost y Dalton, cuando todavía nadie hablaba de atomismo. Hegel sí tuvo ahora perspicacia: siguió a Gilbert con reciente actualidad, y cita a Prévost ${ }^{66}$ en el semestre de 1803/04 y a Dalton ${ }^{67}$ en el de 1805/06. Pero, ¿por qué fue Hegel tan meticuloso al citar a Dalton? Contando con Gilbert, que apuntó al empirismo de la Escuela de Manchester en numerosas ocasiones, no sólo dejaba en evidencia a Schelling, sino que los avances de Dalton refutan también la concepción ilustrada de la materia que explicaba Kant: no hay fuerzas repulsivas entre partículas de dos gases distintos $^{68}$. El apriorismo de afirmación y negación del concepto no corres-

65 Beraud: «Beantwortung der Frage, warum manche Körper durch die Verkalkung an Gewicht zunehmen» en Mineralogische Belustigungen (1771) t. VI: 10.

66 HGW 6: 87.

67 HGW 8: 65.

68 «Sólo conocemos la sustancia en el espacio a través de las fuerzas que actúan en el mismo, sea impulsando hacia él otras fuerzas (atracción), sea impidiendo que penetren en él (repulsión e impenetrabilidad). No conocemos otras propiedades que constituyan el concepto de sustancia que se manifiesta en el espacio y que llamamos materia». Crítica de la Razón pura, B 321. Mientras que Hegel extracta de un artículo de Dalton en los Anales de Física, para su 
ponde con una atracción o repulsión de la materia. Hegel fue el primero en ver que el isomorfismo entre el entendimiento y lo real, propio de las Academias y de la Ilustración, estaba ya quebrado. El experimento como imposición del concepto/tortura a la Naturaleza fracasaba; y el modelo newtoniano, largo tiempo reservado para la futura Química de lo microcósmico, también.

José Luis Yepes Hita

Avd $^{\mathrm{a}} \mathrm{Ntr}^{\mathrm{a}} \mathrm{Sr}^{\mathrm{a}}$ de Atocha, 15

30007 Murcia

jlyepes@um.es

semestre 1805/06, lo siguiente: «(3०) Cuando se mezclan diversos tipos de gases, éstos no [muestran] negatividad entre sí, sino que [se hallan en] tranquila unión[:] irrelevancia del peso específico [para la mezcla; ] sin tener que ver unos con otros, se interpenetran, sin proceso; [pese a su unión, son] productos plenamente neutros, pues su esencia consiste en que se hallan disueltos. No hacen sino difundirse normalmente. Dalton, Gilbert, tomo XIII, página 439[:] "las partículas heterogéneas en mezclas de fluidos elásticos no se repelen entre sí, [cuando se hallan] a las distancias en que se repelen las partículas homogéneas de un solo fluido" (es decir, que tienen existencia como mera materia; existe la continuidad, ser-en-sí en su externalidad, diferencias que no lo son) "y cuando se les pone en verdadero contacto entre ellas, la resistencia que se ofrecen es en todo la de los cuerpos rígidos". "Las partículas de un tipo de gas se sustentan exclusivamente en las partes homogéneas del mismo tipo de gas, pese a que, si fueran visibles, parecería como si descansaran inmediatamente en las partículas heterogéneas de otra especie de gas", "por cada parte de masa hay 1000 y más huecos". [Las partículas se] mezcla[n], en vez de separarse según [el] peso específico; su diversa extensión debida al calor no las dispersa[.]». HGW 8: 65. 